\title{
Racionalidade e saberes para a universalização do saneamento em áreas de vulnerabilidade social
}

\author{
Rationale and knowledge for the universal implementation \\ of sanitation in areas of social vulnerability
}

Ester Feche Guimarães de Arruda Juliano ${ }^{1}$

Laura Camargo Macruz Feuerwerker ${ }^{2}$

Sonia Maria Viggiani Coutinho ${ }^{2}$

Tadeu Fabrício Malheiros ${ }^{2}$

\footnotetext{
${ }^{1}$ Núcleo de Pesquisa em

Saneamento (NUPS),

Departamento de Pósgraduação, Ciências da Engenharia Ambiental, Universidade de São Paulo. Rua Costa Carvalho 300, Pinheiros. 05429-900 São Paulo SP.

feche.guimaraes@gmail.com

${ }^{2}$ Faculdade de Saúde

Pública, Universidade de

São Paulo.
}

\begin{abstract}
The adoption of principles of equality and universality stipulated in legislation for the sanitation sector requires discussions on innovation. The existing model was able to meet sanitary demands, but was unable to attend all areas causing disparities in vulnerable areas. The universal implementation of sanitation requires identification of the know-how that promotes it and analysis of the model adopted today to establish a new method. Analysis of how different viewpoints on the restructuring process is necessary for the definition of public policy, especially in health, and understanding its complexities and importance in confirming social practices and organizational designs. These are discussed to contribute to universal implementation of sanitation in urban areas by means of a review of the literature and practices in the industry. By way of conclusion, it is considered that accepting a particular concept or idea in sanitation means choosing some effective interventions in the network and on the lives of individual users, and implies a redefinition of the space in which it exercises control and management of sewerage networks, such that connected users are perceived as groups with different interests.
\end{abstract}

Key words Universality, Sanitation, Vulnerability, Health, Innovation
Resumo A adoção de princípios de equidade e universalidade previstos na legislação do setor de saneamento demanda discussões sobre inovação. O modelo existente foi capaz de suprir demandas sanitárias, mas não conseguiu atender todas as áreas do país, restando disparidades em regiões carentes. A universalização do saneamento exige identificação dos saberes que irão promovê-la $e$ análise do modelo hoje adotado, para chegar-se a nova proposição. Exige reflexão de como diferentes visões sobre o processo de saneamento são percebidas e consideradas para definição de politicas públicas, especialmente na saúde, e na compreensão de suas complexidades e importância na confirmação de práticas sociais e de desenhos organizativos. Os modelos organizativos e dispositivos são debatidos para contribuir à universalização dos serviços em áreas urbanas por meio da revisão bibliográfica e avaliação de práticas do setor. Como conclusão, entende-se que aceitar um determinado conceito ou ideia em saneamento implica escolher certas intervenções efetivas sobre a rede e a vida dos usuários individuais, e implica uma redefinição do espaço em que se exerce o controle e gestão das redes de saneamento, de modo que os usuários conectados sejam entendidos como coletivos com diferentes interesses.

Palavras-chave Universalização, Saneamento, Vulnerabilidade, Saúde, Inovação 


\section{Introdução}

A Constituição Federal do Brasil ${ }^{1}$ estabelece as diretrizes gerais do saneamento, regulamentadas por meio da Lei Federal no 11.445 , de 05 de janeiro de $2007^{2}$, e estabelece a saúde como direito de todos e dever do Estado em provê-la, de modo a reduzir os riscos de doenças a partir do acesso universal e igualitário aos serviços de promoção, proteção e recuperação da saúde. Estabelece também, entre as atribuições do Sistema Único de Saúde (SUS), a participação na formulação da política e da execução das ações de saneamento básico.

Galvão Junior e Paganini ${ }^{3}$, Teixeira e Pungirum $^{4}$ e Andreazzi et al. ${ }^{5}$, entre outros, analisam as externalidades positivas do saneamento sobre a saúde pública. Juliano et al. ${ }^{6}$ abordam os estudos econométricos que correlacionam saneamento e saúde e demonstram, claramente, que a falta de condições adequadas de saneamento, no que se refere à água e ao esgotamento sanitário, é uma das principais causas da mortalidade na infância e interferem na Política de Universalização do Saneamento.

As Metas do Milênio, que foram estabelecidas pelos Estados-membros da Organização das Nações Unidas, preveem a redução pela metade, até 2015 , da proporção da população sem acesso permanente e sustentável à água potável segura e ao esgotamento sanitário. Não obstante estes dispositivos, o saneamento encontra-se em um momento crítico, pois em função das diretrizes da política em construção serão atingidas ou não as metas de universalização, atendendo as normas constitucionais e as metas do milênio.

São diversos os dados disponíveis acerca da cobertura de abastecimento e esgotamento sanitário em áreas legais, porém faltam indicadores adequados para medir as disparidades de gestão e da situação do usuário nas questões da universalização.

De acordo com Silva ${ }^{7}$, o marco referencial de desempenho dos serviços desenvolvidos a partir do modelo do Planasa foram os indicadores de desempenho do Catálogo Brasileiro de Engenharia Sanitária e Ambiental (Cabes), publicado anualmente pela Associação Brasileira de Engenharia Sanitária e Ambiental (Abes), e que sistematizavam os relatórios de desempenho técnico-operacional dos serviços prestados pelas companhias estaduais de saneamento básico. De 1977 até 1995 o Cabes constituiu-se como a única fonte sistemática de dados padronizados de desempenho do setor. A estrutura típica de informações do Cabes, com base no período de 1993 a 1996, mais tarde substituída pelos relatórios do Sistema Nacional de Informações de Saneamento (SNIS), envolve informações relacionadas à cobertura dos serviços e dados e indicadores relacionados ao desempenho operacional. Embora os relatórios mais recentes do SNIS incluam elementos de qualidade na prestação dos serviços - como intermitência, qualidade da água, vazamento de esgoto e atendimento a reclamações - que denotam preocupação com a eficácia da prestação, ainda assim, não constituem diagnósticos voltados à eficácia social.

É importante a escolha de diretivas que garantam informações adequadas e sua inserção nas pautas de discussão do cumprimento das políticas públicas, nos diversos espaços e âmbitos de atuação.

A universalização do saneamento, por sua vez, exige a identificação dos saberes que darão suporte à sua efetivação e a análise do modelo até hoje adotado, composto de técnicas da engenharia e da administração pública, com a finalidade do atendimento ao usuário, tendo por objetivo chegar-se à reflexão e a uma nova proposição para o setor.

O marco regulatório do saneamento ${ }^{6}$ preconiza, nos artigos $2^{\circ}$ e $3^{\circ}$, VII, os princípios fundamentais de universalização do acesso e integralidade, e define subsídios como instrumento econômico de política social para garantir a universalização do acesso ao saneamento básico, especialmente para populações e localidades de baixa renda.

Juliano e Turolla ${ }^{7}$ apresentam as políticas públicas que interferem no setor, mas não conseguem capturar as parametrizações de forma a equacionar o financiamento dos subsídios necessários à universalização.

O Plano Nacional de Saneamento Básico $(\text { Plansab })^{1}$, cuja elaboração foi prevista na lei de diretrizes nacionais para o saneamento básico Lei Federal no ${ }^{\circ} 11.445 / 2007^{2}$, regulamentada pelo Decreto Federal no 7.217/2010 ${ }^{8}$, foi colocado em consulta pública em junho de 2011. Dispõe sobre o equacionamento dos investimentos necessários à universalização e dos subsídios a tarifas, afirmando uma demonstração do bom potencial de investimentos com recursos tarifários. Nesse modelo, outros cidadãos irão, mediante subsídios cruzados, prover o direito dos demais cidadãos em situação de vulnerabilidade, financiando a política social do setor. Nesse sentido, o subsídio cruzado foi um legado do Plano Nacional de Saneamento - Planasa, definido no Decreto 
Federal $82.587 / 78^{9}$, que regulamentou a Lei Federal (revogada) n. 6.528/78 ${ }^{10}$.

Pelo citado Decreto ${ }^{9}$, todas as camadas sociais terão assegurados os serviços de saneamento básico, e as tarifas deverão adequar-se ao poder aquisitivo da população, a fim de compatibilizar aspectos econômicos com objetivos sociais (art.10).

Destarte estes dispositivos, as empresas de saneamento foram estruturadas segundo o modelo hegemônico da engenharia. Em regime de monopólio natural, com normas de sustentabilidade definidas por decreto e pelas regras de acesso a financiamentos. O direito do usuário não é mencionado na lei e o setor é autorregulado.

O Planasa, proveniente de um modelo biopolítico, obteve resultados expressivos, se considerarmos que urgia a ação naquele momento. Havia a demanda sanitária para o todo, o percentual de atendimento era baixíssimo. Assim, o método utilizado era o normal, ou seja, a média se aplicava com bons resultados, pois o déficit de saneamento era imenso. Os programas, projetos e obras focalizaram as áreas urbanas, começando pelos centros e gradativamente estendendo suas ações para as regiões periféricas, estratégia proveniente de modelos de financiamento externos para países em desenvolvimento. Foi priorizado o abastecimento de água, seguido de coleta e afastamento de esgotos. O Brasil não abriu mão das metas da universalização, porém as ações foram insuficientes e os resultados heterogêneos em diferentes áreas do país.

Para iniciar a análise do contexto de sustentação das práticas de saneamento, faz-se necessário um olhar sobre seus sentidos, sob as perspectivas do risco e do cuidado à saúde pública. Em que medida as diferentes visões sobre o processo de saneamento são percebidas e consideradas quando da definição de políticas públicas, dos modos da organização da gestão e do modo de operar o saneamento? Para uma aproximação dessa questão, faz-se necessário explorar a dimensão do saneamento como cuidado à saúde, compreender suas complexidades e importância na confirmação das práticas sociais e dos desenhos organizativos do setor.

E, ainda, há de indagar-se por que se chegou a tamanhas disparidades no atendimento à população? O que explica os diferentes resultados obtidos pelos serviços? A arquitetura do modelo do saneamento se comunica com a natureza do querer dos usuários? Como se explicam os déficits de cobertura de esgoto? Pode-se atribuir essas questões à natureza das formulações das políticas do setor?
A produção da vida nas metrópoles, os modos de viver e o trabalho na contemporaneidade são centrais para se pensar o saneamento. No Brasil, as ações para que o usuário se conecte às redes de esgoto nas metrópoles são objeto da discussão para garantir a universalização. As dificuldades das operadoras dos serviços são reconhecidas como críticas, em especial nas questões dos usuários se conectarem as redes de esgoto, no que diz respeito às práticas de saneamento $e$ relações sanitaristas-usuários.

O objetivo do presente trabalho é desenvolver debate sobre modelos organizativos e dispositivos que possam contribuir à universalização dos serviços em áreas urbanas.

\section{Metodologia}

O artigo é resultado das discussões da disciplina Racionalidade e Micropolíticas na Produção dos Modelos Tecno-Assistenciais da Pós-graduação da Faculdade de Saúde Pública da Universidade de São Paulo. Está fundamentado em metodologia qualitativa de pesquisa e recursos metodológicos multivariados de coleta de dados: Pesquisa Bibliográfica que identifica as práticas sociais afinadas com um modelo hegemônico de pensar a saúde, doença e soberania do Estado sobre os cidadãos; Pesquisa Documental de acesso restrito das práticas anti ou contra-hegemônicas das concessionárias do mesmo período e matérias de jornais sobre a universalização em áreas de vulnerabilidade; Tomada de Apontamentos com a construção de paráfrases apoiadas nos autores pesquisados numa crítica às práticas do setor de saneamento para a composição de citações; observação de campo da atuação conjunta dos trabalhadores sanitaristas e representantes das fiscalizações municipais; observação participante na tomada de testemunhos objetivando uma reflexão do modelo hegemônico do saneamento e proposição de novos conceitos e modos de operar nas áreas urbanas por Bauer e Gaskell ${ }^{11}$, Den$\operatorname{zin}^{12,13}$ e Quivy e Van Campenhoudt ${ }^{14}$.

\section{Saneamento e o Modelo Hegemônico}

Para Foucault ${ }^{15}$, os diferentes desenhos sanitários desenvolvidos na Alemanha, França ou Inglaterra apresentavam aspectos influenciados, não apenas pelo econômico, mas também pelo político. Vê-se então, a produção de uma medicina sanitária de estado, quando já se adotava o enfoque técnico, pela norma, pela média, grupo, 
tipo e não pelo indivíduo, com a organização de um sistema de observação da morbidade e normalização das práticas. Assim, ocupavam-se com a contagem da população, dos adoecimentos, dos números totais de mortes ocorridas ou evitadas, efetivavam sistemáticas de afastamento para as periferias dos focos de contaminação e procedimentos de medicalização.

O planejamento urbano incluindo ações sanitárias ocorreu pela primeira vez em 1767, com o Plano de Urbanização de Paris, elaborado por Moreau. A medicina urbana instituiu métodos de vigilância e hospitalização. Os problemas provenientes das aglomerações humanas, que ocorriam motivadas pelo mercantilismo, contaminaram as águas por diversas razões: o amontoamento de mortos no Cemitério dos Inocentes no centro de Paris, curtumes e outras atividades às margens do rio. Começam então a ser implantadas medidas sanitárias para afastar das cidades fontes de contaminação e também a população vulnerável, que naquele momento representavam risco de endemias à burguesia. Desta forma, é feita a primeira setorização separando ricos e pobres de Paris.

Para Madel ${ }^{16}$ as medidas sanitárias, como proteção da saúde, constitutiva da lógica do capitalismo, fazem parte de um modo de organizar a saúde. Nesse sentido, de forma semelhante, o saneamento tem um plano de produção com uma lógica de constituição política, econômica, social e ambiental de atendimento à sociedade. $\mathrm{O}$ saneamento, como medicina das coisas: água, ambiente e parte do cuidado da saúde pública, é a forma de transformar a sede e a necessidade fisiológica do ser humano em necessidades sanitárias, que demandam serviços essenciais, centrando-os no domicílio. Nesse modelo, o saneamento provê o direito humano essencial mediante o abastecimento de água e saneamento de esgotos, onde houver possibilidade de intervenção sanitária com sustentabilidade. A legitimação do saber científico se constitui, então, como única forma de produzir o conhecimento da engenharia sanitária. A ciência rejeita a subjetividade no saber científico, em especial na conexão domiciliar. No plano da racionalidade, concluídas as obras de saneamento a universalização será atingida com a conexão intradomiciliar feita pelo usuário. Essa é a matriz fundante do saneamento.

Há produção de sentido, pois o saneamento é uma ferramenta de equidade no atendimento a um direito humano essencial, porém seguem indefinidos os lugares do ser humano e do usuário nesse modelo. É necessário um questionamento quanto à escolha de se olhar o usuário dos serviços de saneamento de forma objetiva, levando-o em conta exclusivamente como ligação domiciliar, de forma que a racionalidade implica em ordem dos sentidos.

Foucault ${ }^{15}$ sugere abandonar a fragmentação das formas de saber. Não é apenas no plano científico que ocorre a produção do conhecimento, ela também se dá nos planos da vivência do usuário.

Merhy ${ }^{17}$ propôs visualizar as práticas operativas para compreender as estruturações produtivas do setor da saúde, considerando tecnologias e saberes dos usuários por meio de caixas de ferramentas, classificando-as da seguinte forma: a primeira caixa é a da propedêutica e procedimentos, a segunda dos saberes e a terceira é a das relações trabalhadores e usuários. Essa estrutura questiona o modelo hegemônico do cuidado a saúde, que desconsidera o usuário, e propõe a classificação do trabalho em morto e vivo: trabalho morto é o que está disponível no momento dos atos de saúde, mas já foi produzido anteriormente; trabalho vivo é o que acontece em ato, no momento do encontro entre trabalhadores e usuários e que responde à singularidade das situações. Além disso, classifica as tecnologias em duras, que englobam equipamentos, normas etc., disponíveis para utilização de determinado modo; leve-duras, que são os conhecimentos estruturados, também disponíveis em geral para serem usados de um certo modo, mas passíveis de adaptação segundo a singularidade das situações e leves, que seriam as tecnologias utilizadas na produção de relações, tais como a escuta, o interesse, o vínculo, o conhecimento dos modos de viver etc.

Fazendo uma analogia, pode-se considerar um conceito do saneamento quanto ao modo de operar de três formas: a primeira vinculada aos mecanismos de implantação das políticas públicas, a segunda aos saberes técnicos e a última às relações sanitarista-usuário. Cada uma delas expressando processos produtivos dos produtos e serviços:

O primeiro grupo é o que permite elaborar o projeto, levantar dados de planejamento, estabelecer metas e programas. Este compreende todos os equipamentos necessários aos diagnósticos, às obras e à prestação dos serviços de saneamento para operação das redes e execução das normas. Sobressai a supervalorização do trabalho do engenheiro, comparativamente aos demais profissionais do saneamento, a centralidade das redes catalisando todas as tecnologias e equipa- 
mentos a seu serviço. Esses processos são produzidos a partir de trabalho morto e trabalho vivo de seus operadores. A esses processos chamamos tecnologias duras.

O segundo grupo permite ao sanitarista exercer uma atuação sobre o usuário de forma a considerar seu universo e necessidades segundo outro prisma. Esse é um modo de sanear considerando saberes do trabalho morto, de forma que a implementação, combinada com a emergencialidade da operação do serviço em execução, em interação com o usuário, transforma-se em trabalho vivo. É uma interface tênue entre a dureza da operação e o pensamento estruturado com a leveza exigida pelo usuário. Nessa situação a tecnologia ganha sentido como atos de saneamento. A essas chamamos tecnologias leve-duras.

O terceiro grupo promove um modelo singular, produzido mediante uma construção conjunta sanitarista-usuário. Ela ocorrerá por considerar o contexto, o modo de vida do usuário, as possibilidades de interagir, o que ampliará as possibilidades de atuação do sanitarista em atos de saneamento, evidenciando a relevância do trabalho vivo. A esse grupo chamaremos tecnologias leves. A tecnologia leve avalia a singularidade do usuário em termos de local, forma de vida, crenças e outros fatores que habitualmente não são considerados.

Nesse sentido, entende-se que habitualmente o saneamento opera olhando a população e o coletivo e não o indivíduo-usuário, de forma que a produção no modelo hegemônico da engenharia focaliza os resultados de massa e evidencia-se pela tecnologia dura. Ao sanitarista interessará conhecer outros saberes que surgirão da relação usuário-sanitarista, evidenciando a relevância do trabalho vivo. O usuário assim teria condições de participar na produção de soluções classificadas como tecnologia leve, que seriam a construção de modelos de operar de forma participativa com o usuário.

Há diferenças entre o ponto de vista do trabalhador-sanitarista e do gestor em relação a como o usuário deva organizar sua vida em função da implantação de uma rede de esgoto, e a visão do próprio usuário.

O saneamento opera em modelo hegemônico rede-centrado. Pressupõe-se que o morador de uma área de vulnerabilidade social deva mudar seu modo de vida em função da nova rede de esgoto, assentada pela concessionária. Ele fará uma pequena obra dentro de seu domicílio para conectar-se à rede recentemente assentada. No caso de o usuário, motivado por suas razões, não se conectar, o gestor criou dispositivos e normas com o intuito de obrigá-lo a conectar-se, sob a pena de ser enquadrado na legislação de crimes ambientais.

A disputa de saberes, de forma a amenizar a gravidade das questões de atendimento e universalização, aborda com naturalidade a institucionalização da crueldade dos termos propostos na universalização. Esta é a racionalidade caracterizada pelo trabalho morto, que vai produzindo sentido e organizando os modos de viver da sociedade com base sobretudo em tecnologias duras.

A produção de políticas deve contemplar não apenas o racional, mas a prática constante. Se o modelo é dado pela viabilidade econômico-financeira do investimento realizado para projeto e obra, calculados tomando por remuneração as tarifas arrecadas após a conexão, o gestor cria normas para todos se conectarem.

Dentro da racionalidade das melhores técnicas de saneamento são construídos modelos diversos de atendimento. Muitos deles são coercitivos e desconsideram as iniquidades, que segundo Berlinguer ${ }^{18}$, são as diferenças injustas derivadas de comportamentos insalubres, quando a escolha do indivíduo é claramente limitada e marcada por condições de vida estressantes e insalubres.

Considerando-se os conceitos de Biopolítica e Biopoder, propõem-se uma compreensão das relações que se estabelecem nessas questões do saneamento.

Merhy $^{19}$, citando Foucault, afirma que a associação entre coerção e convencimento é vital para a construção de um agir diferente, que opera as relações de poder na legitimidade de dispor da vida por meio de mecanismos de submissão e domínio, e operar assim por biopoder.

Num exemplo real, em área de vulnerabilidade social uma usuária é acionada por uma prefeitura por crimes ambientais. Ora, que sentido faz condenar uma dona de casa, idosa e moradora de um domicílio há 30 anos em áreas sem redes de coleta de esgoto à lei de crimes ambientais por não conectar-se a nova rede, obrigandoa sob as penas da lei a tornar-se usuária?

O saneamento assim, opera por biopolítica, termo forjado por Foucault para designar uma das modalidades de exercício do poder sobre a vida, sobre a população, enquanto massa global afetada por processos de conjunto.

Pelbart ${ }^{20}$ fez uma análise crítica sobre o pensamento cientifico hegemônico que produz afirmações como verdades para obter resultados sobre a saúde coletiva, desconsiderando o im- 
passe e os limites provenientes dos modos de viver e saberes do usuário.

O modelo engenheiro-hegemônico orienta e influencia a formação de profissionais do saneamento e as decisões empresariais, mas a despeito da luta pela universalização, não conseguiu equacionar as questões de sustentabilidade do setor, sendo que os maiores custos dos investimentos estão concentrados em redes que muitas vezes não receberão a conexão dos usuários.

Que lugar as práticas de engenharia sanitária ocupam no Brasil? O tema do domicílio e usuário no aspecto racional e social, e a forma como é considerado no saneamento, ainda não possibilitam visibilizar tensões e produzir soluções efetivas na política pública de saneamento. A política se esquiva da abordagem das iniquidades. Dentro das nossas democracias, temos sistemas totalitários que não consideram a ética da responsabilidade e da saúde publica. São desconsideradas as externalidades do setor sobre a saúde coletiva e o equacionamento da universalização mediante subsídios é sistematicamente negado pelo Estado e seu equacionamento é omitido.

Feuerwerker ${ }^{21}$, na sua análise sobre os modelos tecnoassistenciais, gestão e organização do trabalho em saúde pública, afirma que atualmente não se pode dizer que continue existindo um movimento sanitário, como um movimento social organizado e militante, mas sim atores mobilizados por tentar construir um sistema de saúde que se aproxime das proposições originais da Reforma Sanitária.

Paim $^{22}$ relata a Reforma Sanitária no Brasil e o abandono na agenda dos temas como medicina social, sendo necessário um avanço na abordagem da interssetorialidade para o cuidado à saúde.

Como tratar as conexões intradomiciliares de pessoas em vulnerabilidade social? Pessoas em situação de vida nua, como em campos de refugiados, quando o que lhes resta são apenas seus corpos, poderão se conectar as redes segundo as condições que lhes impusemos? Como abordar a universalidade do saneamento com tecnologias duras como domicílios sem considerar os usuários e seus saberes? Sabemos que há produção da vida e produção do pensamento por esse usuário. Eles estão imbuídos de necessidades e aspirações. Eles são o sujeito da ação e decidem pela conexão ou não, conforme essa conexão lhes faça sentido. E dentro de sua ordem de prioridades.

\section{Outros Saberes são Necessários à Universalização}

É necessário desnaturalizar as formas de gerir e operar o saneamento com base sobretudo em normas, assim como a relação do sanitarista com o usuário das redes. Devemos mudar a centralidade das redes e domicílios para um modelo usuário-centrado.

A partir do agir científico, segundo Merhy ${ }^{19}$, há uma deslegitimação dos outros saberes e das vivências dos usuários, que não são ouvidos ou considerados no cuidado à saúde coletiva.

A reversão dessa situação faz-se mediante o trabalho vivo, em que exista a criação, que suplante o trabalho morto. Esse último, por inflexível, se apresenta em formas que não conseguem garantir uma adesão do usuário às redes. Não possibilita conversa com as diferentes realidades.

Para atingir a universalidade nas áreas urbanas remanescentes é necessário um trabalho vivo. Há necessidade de um importante movimento de reconhecer que o usuário tem saberes a partir de suas limitações, vivências, educação e informações. E, acima de tudo, tem suas razões. A universalização será construída de múltiplos modos. Hoje, por mais avançadas que estejam as soluções tecnológicas, a universalidade não se fará na lógica da tecnologia dura, que trata a universalização como um projeto de conexão a uma casa vazia, sem usuários. Dentro do domicílio há um usuário com autonomia.

A estruturação do trabalho de forma a reconhecer o usuário como gestor legítimo de suas decisões, que tem valores, saberes e uma situação social que produz singularidade, permite construir um arranjo, em que o gestor e o trabalhador sanitarista colocam o seu saber a disposição do usuário na construção de uma solução coerente com o diagnóstico e disponibilidade de recursos.

A constituição da hegemonia cientifica não tem eliminado outros saberes. O grau de autonomia dependerá da condição e conhecimento do usuário. Dependemos de uma conexão de produção e encontro do saber técnico a favor do usuário. Em determinadas situações não se consegue impor o saber técnico, por ser necessária uma composição dos saberes diversos. O trabalho vivo, quando instituído por uma combinação de tecnologias leves e duras em favor do usuário obterá resultados constituídos de legitimidade e considerações que os demais modelos não propiciam. Uma integração que ocorrerá entre racional e social. 
Caponi $^{23}$ afirma que há uma singularidade presente, pois nem todas as situações são de "livros", ou seja, correspondentes à média. Supõe-se uma integração necessária com o usuário para implantar uma tecnologia, uma vez que o projeto depende do querer do usuário para sua finalização.

Necessário entender o que compõe o campo da produção do cuidado da saúde como sanitaristas. São a mortalidade infantil e as doenças de veiculação hídrica, e não os indicadores de cobertura e atendimento, desconsiderando os assentamentos em áreas irregulares, que estabelecem a condição sanitária nos centros urbanos.

No campo das tecnologias leves, é a participação social, a decisão do usuário e a negociação entre gestores, sanitaristas e usuários, que permitirá exercer seus saberes a favor da política de saneamento nos princípios que a norteiam.

A intervenção sanitária, mediante um modelo usuário-centrado em que a hegemonia na decisão é a do usuário, será a forma de reduzir sofrimentos, doenças e mortes, propiciando as externalidades positivas do setor sobre a saúde coletiva.

A pretensão de normalizar a vida das pessoas supõe uma submissão voluntária para adesão dos novos usuários das redes de esgoto, que não acontece na prática.

A centralidade no usuário deve ser a principal ferramenta analítica para o setor de saneamento. Entretanto, como identificar os diferentes saberes, e qual estratégia de gestão a ser adotada?

\section{Um Novo Modelo de Gestão para o Saneamento}

A I Conferência Internacional em Promoção da Saúde da Organização Mundial da Saúde ${ }^{24}$ definiu a Promoção da Saúde como "o processo de capacitação na comunidade para atuar na melhoria da sua qualidade de vida e saúde, incluindo uma maior participação no controle deste processo". Obteve-se um consenso de que determinantes sociais de bem estar e qualidade de vida, provenientes de políticas intersetoriais, eram diretivas para reorientação do setor da saúde para que se apoiassem os usuários à articulação com demais setores, extrapolando o papel provedor de serviços da saúde.

Nesse momento, ampliou-se a compreensão da saúde, das externalidades dos setores sobre os custos dos serviços de saúde, e da importância do usuário. Houve um convite à participação dos demais setores mediante a focalização de políticas integradas. Foi definido o papel do Es- tado na produção de políticas considerando a intersetorialidade, e reconhecida a centralidade da sociedade civil empoderada pela mobilização, participação e controle social, chamado de empowerment.

Faleiros et al. ${ }^{25}$ utilizam o conceito de empowerment para o Sistema Único de Saúde (SUS), entendido como o processo de fortalecimento pelo aumento do saber e articulação do usuário, compreensão crítica da conjuntura, exercício de direitos e construção de estratégias de poder político, conquista e usos de recursos econômicos, entre outros fatores importantes na dialética de transformação das relações com o usuário.

Becker et al. ${ }^{26}$, ao analisarem o conceito de empowerment, afirmam que o trabalho comunitário assim orientado, fortalece o tecido social pelas interações que promove e confere poder ao sujeito social envolvido, conferindo legitimidade e importância para a questão da influência em políticas públicas.

É necessária a criação de um saneamento comunitário, contando com uma intensa mobilização popular e intelectual, em torno de questões como direitos humanos e pobreza. Deve-se buscar uma nova racionalidade para os serviços de saneamento, reconhecendo-se o distrito sanitário, a hierarquização dos serviços, a participação comunitária e a introdução de outras categorias profissionais no saneamento.

Assim, partindo da política pública e de uma postura que leve em conta outras perspectivas, é necessário adentrar nas micropolíticas do saneamento, na lógica da racionalização (hierarquização do atendimento ao saneamento) e discussão da descentralização para os planos, programas, projetos.

Para Cecílio ${ }^{27}$, a gestão inovadora e alternativa a um modelo organizativo hegemônico será uma gestão colegiada em que o compartilhamento da gestão é constitutivo. As formulações iniciais desses grupos são marcadas pela preocupação com a melhor representação possível dos trabalhadores provenientes de diversos níveis e processos da organização, visando à constituição de espaço coletivo de contraste, disputa e composição das diferentes visões e interesses dos atores organizacionais, na perspectiva de uma prática mais solidária, menos autocentrada e mais cuidadora dos usuários.

Nesse modelo existe um espaço de compartilhamento autorizado pela gestão, que reconhece a produção micropolítica com autonomia e busca soluções mais próximas do cotidiano. Trabalhadores e usuários compondo a gestão propo- 
rão uma nova forma de operar o saneamento. Eles criarão um projeto sanitário singular, como tentativa de aproximação da gestão ao usuário, utilizando ferramentas que permitam a implantação de espaço de discussão do dia-a-dia para revisão do trabalho, de forma a garantir a integralidade, a equidade e a universalidade.

Nesse sentido, a aprendizagem e a atitude transformadora provêm do reconhecimento do distanciamento dos modelos quando confrontados com a realidade da prática profissional, de forma a promover mudanças. A despeito das disputas que surgirão nesses espaços, essa é a oportunidade de levar-se à organização soluções contextualizadas e reflexões dos gestores.

O modelo sanitarista hegemônico passou por um alto grau de sofisticação gerencial Toyotista. Um modelo fundamentado no planejamento estratégico que considera, captura e compra o trabalho vivo, promove o desejo de trabalhar e de estar inserido num programa de metas e remuneração. O planejamento estratégico por objetivos é fundamental para identificar problemas críticos e permite a análise de governabilidade, fundamental para sabermos com o que se pode contar em termos de instrumentos e recursos. Porém, a centralidade desse modelo é determinada pelo querer dos gestores dentro da viabilidade de alcançar metas estabelecidas por eles mesmos.

Doutra forma, o planejamento estratégico situacional de Matus $^{28}$, em substituição ao planejamento estratégico, foi utilizado nos movimentos sociais para interferir na agenda política, uma vez que estabelece uma estratégia de trabalho em situação de poder compartilhado, pois um dos recursos que restringem nossas capacidades de ação são as restrições de poder.

A construção desse planejamento faz-se pautada na realidade da relação sanitarista-usuário, que consideram o querer do usuário e as possibilidades da operadora. Esta também pode ser uma ferramenta para a construção de uma gestão compartilhada. Isto posto, os indicadores de sustentabilidade ocupariam papel central nesse processo, pois podem ser usados como ferramenta de mobilização das partes interessadas, para análise e avaliação da universalização do saneamento e das ações necessárias.

Hubbard ${ }^{29}$ inseriu duas perspectivas para a gestão do saneamento por meio do "Sustainability Balanced Score Card (SBSC)": a social, cuja pergunta é "Qual o impacto dos serviços nas comunidades?”; e a ambiental, cujas perguntas são "como usamos nossos recursos e o que desperdiçamos para criar nossos produtos e serviços?”.
Construir indicadores de sustentabilidade para o setor de saneamento exige parcerias entre os diversos atores desta arena, no sentido de que os indicadores sejam efetivamente inseridos na regulação, na tomada de decisão, desde o usuário às concessionárias de serviços de saneamento e setor governamental.

Bos and Smout ${ }^{30}$, Connors and Sanyal ${ }^{31} \mathrm{e}$ Evans and Harris ${ }^{32}$ analisam a quebra de paradigmas do nível de burocracia sob o ponto de vista das normas das utilities e afirmam que o trabalhador no aspecto individual quer ajudar os outros, mas na vida real enfrenta uma miríade de dilemas e desafios para superação que são limitados por recursos e políticas obscuras e omissas.

Connors and Sanyal ${ }^{31}$ analisaram como os procedimentos e as normas são executados pelos trabalhadores e o que faz com que eles se dediquem às tarefas. Seu olhar ajudador provê um arranjo para avaliar e construir novos desenvolvimentos no campo.

Além deste enfoque integrador, são necessárias pesquisas e esforços no entendimento das relações ambiente-sociedade, que entremeiem o setor, bem como dos aspectos políticos e da gestão, de forma a incorporar estrategicamente um olhar sobre as iniquidades desconsideradas no modelo hegemônico do saneamento.

\section{Considerações Finais}

A defesa da universalização pelo modelo hegemônico da engenharia contribui para o estabelecimento de prioridades, porém a demanda espontânea também é um revelador das necessidades do ponto de vista dos usuários. A oferta não será capaz de disciplinar a demanda, pois esta representa escolhas que o usuário faz.

As políticas públicas sustentadas na Constituição Federal ${ }^{1}$ de 1988 e no marco regulatório do saneamento com os direitos preconizados são pontos de apoio e guias para as mudanças que demandam ações de trabalho vivo organizado para iniciativas e esforços de transformação em realidades vivas, que promovam profunda reorganização do setor de saneamento.

O certo é que aceitar um determinado conceito ou ideia em saneamento implica escolher certas intervenções efetivas sobre a rede e a vida dos usuários individuais, e implica ao mesmo tempo, uma redefinição deste espaço em que se exerce o controle e a gestão das redes de saneamento, às quais os indivíduos estarão conecta- 
dos, entendidos como grupo humano, como população.

Um bom sanitarista deverá promover formas de o poder público compreender que as externalidades sobre a saúde são suficientes justificativas à constituição de um programa de financiamento de subsídios como promoção à saúde, prevenção das doenças e dos danos, e erradicação das iniquidades, pois o risco é o produto da vulnerabilidade.

Aos reguladores caberá desempenhar suas atribuições utilizando-se de mecanismos que efeti- vamente considerem as iniquidades, bem como as dinâmicas justificativas do setor para o não atendimento dos princípios do marco regulatório.

Os sanitaristas-trabalhadores e os gestores do saneamento deverão auxiliar as concessionárias a deslocarem a centralidade do saneamento da rede para o usuário, operando em planos em que o modelo organizativo da gestão considere todos os saberes que contribuem para a universalidade.

Finalmente, um bom sanitarista deverá contribuir na tarefa de dar sentido a cada usuário daquilo que não é evidente.

\section{Colaboradores}

EFGA Juliano, LCM Feuerwerker, SMV Coutinho e TF Malheiros participaram igualmente de todas as etapas de elaboração do artigo.

\section{Referências}

1. Brasil. Proposta de Plano Nacional de Saneamento Básico - Plansab. Ministério das Cidades. [on line]. [acessado 2010 jun 25]. Disponível em: http:// www.cidades.gov.br/images/stories/ArquivosSNSA/ PlanSaB/VP_Plansab13042011.pdf

2. Brasil. Lei Federal $n^{\circ}$ 11.445. Estabelece diretrizes nacionais para o saneamento básico. Diário Oficial da União 2007; 08 jan.

3. Galvão Junior AC, Paganini WS. Aspectos conceituais da regulação dos serviços de água e esgoto no Brasil. Engen Sanit e Ambient 2009; 14(1):79-88.

4. Teixeira JC, Pungirum MEMC. Análise da associação entre saneamento e saúde nos países da América Latina e do Caribe, empregando dados secundários do banco de dados da Organização Pan-Americana de Saúde - OPAS. Rev. bras. epidemiol 2005; 8(4):365-376

5. Andreazzi MAR, Barcellos C, Hacon S. Velhos indicadores para novos problemas: a relação entre saneamento e saúde. Rev Panam Salud Publica 2007; 22(3):211-217.

6. Juliano EFG, Coutinho SMV, Prota MG, Malheiros TF. Inter-relações ambiente e saúde no uso de poços oficiais para consumo humano em áreas de contaminação dos recursos hídricos subterrâneos. Revista Saúde em Debate 2012; 36(N. Especial):85-97.

7. Silva RT. Pesquisa em saneamento - elementos para uma tecnologia socialmente inclusiva. In: $3^{a}$ Conferência Nacional de Ciência Tecnologia e Inovação. Brasília; 2005. 
8. Brasil. Decreto Federal no 7.217/2010, de 21 de junho de 2010. Regulamenta a Lei no 11.445 , de 5 de janeiro de 2007, que estabelece diretrizes nacionais para o saneamento básico, e dá outras providências. Diário Oficial da União 2010; 22 jun.

9. Brasil. Decreto Federal n. 82.587 de 6 de novembro de 1978. Regulamenta a Lei $n^{\circ} 6.528$, de 11 de maio de 1978, que dispõe sobre as tarifas dos serviços públicos de saneamento e dá outras providências. Diário Oficial da União 1978; 07 nov.

10. Brasil. Lei federal n. 6.528 (revogada pela Lei 11.445/ 2007) de 12 de maio de 1978. Dispõe sobre as tarifas dos serviços públicos de saneamento básico, e dá outras providências. Diário Oficial da União 1978; 12 maio.

11. Bauer MW. Gaskell G, editors. Pesquisa qualitativa com texto, imagem e som: um manual prático. $3^{\mathrm{a}}$ Edição. Petróplis: Vozes; 2002.

12. Denzin NK. Sociological methods: a sourcebook. Chicago: Aldine; 1970.

13. Denzin NK. The research act: a theoretical introduction to sociological methods. Chicago: Aldine; 1970.

14. Quivy R, Van Campenhoudt L. Manual de investigação em ciências sociais. 3a Edição. Lisboa: Gradiva; 2003.

15. Foucault M. Microfísica do poder. Rio de Janeiro: Graal; 1979.

16. Madel TL. Natural, racional, social: razão médica e racionalidade científica moderna. Rio de Janeiro: Campus; 1979.

17. Merhy EE. Um ensaio sobre o médico e suas valises tecnológicas: contribuições para compreender as reestruturações produtivas do setor saúde. Interface Comun Saúde Educ 2000; 4(6):109-116.

18. Berlinguer G. Ética da Saúde. São Paulo: Hucitec; 1996.

19. Merhy EE. Gestão da produção do cuidado e clínica do corpo sem órgãos: novos componentes dos processos de produção do cuidado em saúde. desafios para os modos de produzir o cuidado centrados nas atuais profissões. Universidade Federal Fluminense. Instituto de Saúde da Comunidade Pós-Graduação em Saúde Coletiva; 2007. [acessado 2011 out 29]. Disponível em: http://www.uff.br/saudecoletiva/professores/merhy/artigos-25.pdf

20. Pelbart PP. Biopolítica e Biopotência no coração do Império. [on line].Version originale de Pouvoir sur la vie, puissance de la vie, Multitudes 9; mai-juin 2002. [acessado 2012 ago 11]. Disponível em: http:// multitudes.samizdat.net/Biopolitica-e-Biopotencia -no
21. Feuerwerker LM. Modelos tecnoassistenciais, gestão e organização do trabalho em saúde: nada é indiferente no processo de luta para a consolidação do SUS. Interface Comun Saúde Educ 2005; 9(18): 489-506.

22. Paim JS. Reforma Sanitária Brasileira: contribuição para a compreensão e crítica. Salvador, Rio de Janeiro: Edufba, Editora Fiocruz; 2008.

23. Caponi S. A saúde como abertura ao risco. In: Czeresnia D, Freitas CM de, organizadores. Promoção da Saúde: conceitos, reflexões, tendências. Rio de Janeiro: Editora Fiocruz; 2003. p. 55-77.

24. Organização Mundial da Saúde (OMS). Carta de OTTAWA. Primeira Conferência sobre a Promoção da Saúde. Ottawa, novembro de 1986.

25. Faleiros V P, Vasconcelos LCF, Silva JFS, Silveira RMG. A construção do SUS: histórias da Reforma Sanitária e do Processo Participativo. Brasília: Ministério da Saúde; 2006.

26. Becker D, Edmundo K, Nunes NR, Bonatto D, Souza R. Empowerment e avaliação participativa em um programa de desenvolvimento local e promoção da saúde. Cien Saude Colet 2004; 9(3):655-667.

27. Cecílio LCO. Colegiados de gestão em serviços de saúde: um estudo empírico. Cad Saude Publica 2010; 26(3):557-566.

28. Matus C. Política, Planejamento e Governo. Brasília: IPEA; 1993.

29. Hubbard G. Measuring organizational performance: beyond the triple bottom line. Adelaide Graduate School of Business. Business Strategy and the Environment 2009; 18(3):177-191.

30. Bos A, Smout I. The role of engineers in the demand responsive approach: a case study from South Africa. Loughborough: WEDC, Loughborough University; 2001.

31. Connors G, Sanyal B. Watering the slums: how a utility and its street-level bureaucrats connected the poor in Bangalore [Thesis]. Massachusetts: Massachusetts Institute of Technology; 2007.

32. Evans T, Harris J. Street-Level Bureaucracy, Social Work and the (Exagerated) Death of Discretion. $\mathrm{Br}$ J Soc Work 2004; 34(6):871-895.

Artigo apresentado em 30/04/2012

Aprovado em 17/07/2012

Versão final apresentada em 30/08/2012 